\title{
Chapter 11 \\ Global Citizenship Education in Canada and the U.S.: From Nation-Centric Multiculturalism to Youth Engagement
}

\author{
Sarah Ranco, Alexis Gilmer, and Colleen Loomis
}

\begin{abstract}
This chapter examines the historical and current uses of global citizenship education (GCE) in Canada and the U.S. in public schools from primary through secondary levels, with attention to Canada as well as similarities and differences within and across the two countries. We assess how social and political contexts have influenced the definition and operationalization of multiculturalism, civic studies, and global studies in curricula, noting that the neo-liberal perspective has focused on making people an economic powerhouse rather than socially concerned global citizens. In our examination of educational approaches that relate to GCE, we present decolonizing pedagogies, the multiculturalism approach in Canada, as well as culturally responsive and anti-racist pedagogies. To illustrate these issues, we offer an example in the Canadian context and raise the need to prevent GCE from becoming yet another tool for hegemony by the Global North on the Global South, as dominant groups have long defined citizenship. We conclude by proposing that to realize GCE in these two countries, teacher/practitioner and local, national, and international actors must engage youth, and in doing so, power imbalances that prohibit becoming global citizens will be addressed.
\end{abstract}

Keywords Multiculturalism · Identity $\cdot$ Civic studies $\cdot$ Global studies

\footnotetext{
S. Ranco $(\triangle)$

Wilfrid Laurier University, Waterloo, Canada

e-mail: ranc5320@mylaurier.ca

A. Gilmer

University of Waterloo, Waterloo, Canada

e-mail: gilm3440@mylaurier.ca

C. Loomis

Wilfrid Laurier University and Balsillie School of International Affairs, Waterloo, Canada

e-mail: cloomis@wlu.ca
} 


\section{Introduction: A History of Citizenship Education}

What it means to be Canadian or American has been shifting for nearly two centuries. Citizenship education, in contrast, has remained mostly nation-centric with little connection to other countries or to how local views are connected and interdependent to a global worldview. Citizenship curricula have been primarily focused on developing a national identity for primary and secondary school students. This inward attention helped establish the two countries as independent of the United Kingdom, but also contributed to slavery and the development of Indian Residential Schools, which forced Indigenous children's assimilation. Our review of how Global Citizenship Education (GCE) has been used reveals gaps that prevent it from contributing to establishing world peace, human rights, and equality, as well as most of the 17 Sustainable Development Goals (SDGs) to be achieved by 2030 (United Nations 2015). Successfully meeting this international agenda depends on quality education (SDG 4) (Vladimirova and Le Blanc 2016), which, we argue, includes a perspective and implementation of GCE that transcends nationalism. While this chapter pays particular attention to how GCE and other educational pedagogies play out in the Canadian context, examples and histories from the U.S. are interwoven throughout and act as points of comparison.

We begin with an understanding of the tragedies, limitations and accomplishments of previous educational conceptualizations related to GCE in Canada and the U.S. One of the main goals of citizenship education in many countries is to create an allegiance to the nation-state. It was in the eighteenth century when Immanuel Kant introduced the idea of the cosmopolitan citizen who valued an interconnected community across the globe (Evans et al. 2009; Nussbaum 2010). During this period, public schooling was an appealing concept, which focused on teaching national citizenship through a national language, civic values, and national history. Additionally, students from working-class families were expected to use this education to understand and maintain their position in social hierarchies. This process resulted in those in power, shaping the minds of future society to serve their ends and retain control over cultural and ideological narratives (Osborne 2000). This selective approach to citizenship has also been used to oppress marginalized populations. For example, while slaves in both countries built the economies and industries, they were not considered citizens by the dominant group and did not have the right to vote or to obtain an education. The abolition of slavery (1834 in Canada and 1865 in the U.S.) did not grant full citizenship rights. This skewed understanding of citizenship continues to impact contemporary educational systems in both countries through the structuring of school curricula.

Since formation, Canada and the U.S. have developed and imposed a nationcentric education curriculum. In the mid-1800s, both countries established Native American boarding schools and Indian Residential Schools. This schooling forced assimilation and striped Indigenous children of their culture intending to turn them into a colonialist rendition of Canadian citizens (Osborne 2000). Indigenous children were removed from their homes, forbidden to speak their native languages, and subjected to physical labor and abuse. Many children died in these residential 
schools. In the U.S., the passage of the 1975 Indian Self-Determination and Education Assistance Act was the beginning of protecting native languages and tribal involvement in education. In Canada, residential schools continued to operate until 1996, and in 2008, the Canadian government made a Statement of Apology to former students. Although considerable work remains to ensure culturally relevant, quality education for all Indigenous Peoples, the inclusion of more than the national languages in schools (English and French in Canada and English in the U.S.) is starting to be found in both countries. While not yet universal, Indigenous languages, practices and beliefs are present in some pre-primary through postsecondary education systems. Diversifying school content can have many tangible benefits for students. For example, Canada's use of heritage languages in schools improves learning outcomes for pupils (Cummins 1992) and contributes to the agenda of multicultural education by exposing all children to multiple languages. However, despite a review finding that multilingualism is associated with increased learning (e.g., Akkari and Loomis 1998), the U.S. has an ongoing and protracted debate about the use of languages other than English for instructional purposes, and beyond. The history of education as nation-centric and assimilationist has been pervasive.

The beginning of citizenship education itself in the U.S. could be situated in the act of assimilating all individuals living in America into the Anglo-Saxon culture (Banks 2008, 2009). Legal qualifications for citizenship provided the backdrop to schooling on the topic. In the late 1800s to early 1900s non-immigrant white men who owned property were the only citizens allowed to vote. No others had these privileges and rights, including white male immigrants. The history of the Amendments to the U.S. Constitution on voting and citizenship rights are many and varied, so we note only a few. The 14th Amendment (1868) guaranteed citizenship to all male persons born or naturalized in the United States. The 15th (1870) required states to accept votes regardless of "race, color, or previous condition of servitude." Women were not allowed to vote until 1920 (19th Amendment) and in the 1924 Indian Citizenship Act guaranteed the right to citizenship and voting for all Native Americans. Despite Amendments, from 1870 for the next 95 years, some states denied access to voting to racialized groups. The Voting Rights Act of 1965 protected voter registration for racial minorities; however, it was not until 1984 that all U.S. states counted all women's votes, including racialized and Indigenous. In 1918, Canadian women who were proxies for men (e.g., by being wives or sisters) or servants in war, such as nurses, had the right to vote. It was not until 1960 that Canadian women (white, racialized, and Indigenous) obtained the right to vote.

With mass immigration in both countries, immigrants were taught to be shameful of their home culture, family, and language (Banks 2009). For example, MexicanAmericans were punished for speaking Spanish within the classroom (Banks 2008). However, in the late 1960s, the report, An Examination of Objectives, Needs and Priorities in International Education in United States Secondary Schools (written by Becker and Andersen 1969 as cited by Cook 2008) directed more attention towards international education that was initially conceptualized as learning about other cultures and languages. Additionally, the ethnic revitalization, freedom 
movement, and civil rights movements of the 1960s and 1970s saw advocacy for cultural democracy and demanded institutions become more inclusive of needs across ethnicity (Banks 2008, 2009).

It is generally accepted that "global education" was first termed in 1975 by Hanvey as the following five elements: perspective consciousness, knowledge of world conditions, cross-cultural awareness, global systems dynamics, and knowledge of choices (Cook 2008). Kniep (1986) redefined the field, distinguishing four main features: the study of human values, global systems, global issues and problems and global history. In Canada, major national issues including the Quiet Revolution in Quebec and claims by Indigenous Peoples for land rights in the second half of the twentieth century opened an avenue to increase interest in citizenship education. Students learned about the complex cultural identity of Canada, including Anglo-Francophone relations, relations between Canada and the U.S., and the history of displacement of Indigenous Peoples (Evans et al. 2009). Indeed, the first expressions of what would become global education took place with a series of educational Royal Commission Reports in the late 1960s to early 1970s (Cook 2008). According to Cook (2008), the Hall-Dennis Report published in 1969 in Ontario was most influential, which advocated for large-scale education changes in Canada.

Furthermore, the movement toward international development, from 1960 to 1970 in Canadian schools, led to a greater focus on global citizenship. Reflective of these shifts, from the 1970 s to 1990 s, there was significant momentum towards GCE in Canada, with the development of new theories, methods, and models of teaching. Also, by the mid-1970s, there was an expansion of federal support and funding for development aid such as through the funding of the Canadian University Service Overseas, and the establishment of the Canadian International Development Agency (CIDA; Cook 2008). By the mid-1980s, CIDA placed pressure on provincial ministries to sanction global education in the mandated curriculum, as CIDA was funding global education across Canada (Cook 2008). However, since the curriculum is provincially mandated rather than federally, there is no consistent mandate involving the inclusion or emphasis on GCE across provinces and territories within Canada (Evans et al. 2009). As such, while post-secondary educators were advocating for a unified education approach, mandated curriculum was much slower in incorporating global citizenship into Canadian public schools (Mundy and Manion 2008). While the creation of a civics course in 1999 demonstrated a need for citizenship training within public education systems (Cook 2008), by the mid-1990s, global education had begun to lose momentum and was primarily shifted to post-secondary education.

\section{Global Citizenship Education Since 2000}

In the U.S., GCE tends to be taught in social studies classes and is often underrepresented in the curriculum (Rapoport 2009). A study by Rapoport (2010) found that GCE was not mentioned in textbooks, nor were teachers familiar with the content. 
Additionally, teachers felt that they did not have time to cover the topic and that they required more significant support to teach GCE appropriately. Finally, teachers noted that it would be useful if GCE were mentioned in curriculum standards. Myers (2010) conducted a study of a five-week international studies program focusing on globalization and global citizenship which suggests that students recognized two themes connected to the purpose of global citizenship as (a) a moral commitment to improving the world, and (b) requiring legal status. Additionally, the students in Myers's study defined a global citizen as a natural condition of all human beings, but one that required specific characteristics, such as a commitment to bettering the world. These studies showcase that while teachers may not feel confident teaching GCE material in the U.S., in some cases, students can still develop an understanding of global issues and citizenship.

Like the U.S., GCE in Canada is typically taught in social studies-related courses and differences are vast because the curriculum is provincially mandated. In the early 2000s, global education began to receive more support from Canadian government actors, particularly from those working on elementary curricula (Mundy and Manion 2008). In 2001, a report entitled Education for Peace, Human Rights, Democracy, International Understanding, and Tolerance, was released by the Council of Ministers of Education Canada, which described themes of GCE (Evans et al. 2009). Although policies were increasing, GCE was still not well represented in the classroom. Components of GCE can be found scattered across provincial curricula, typically within social studies courses (Evans et al. 2009).

Indeed, a curriculum analysis across seven provinces, suggesting that the extent to which GCE is addressed in the mandatory curriculum is quite variable. For example, while the provinces Alberta, Manitoba, Nova Scotia, and Yukon have mandated a specific grade in which students learn about global issues, Ontario and Quebec curricula mention GCE themes but do not place a strong focus on these issues. Additionally, while most officials agree that GCE should be a mandatory part of curricula, it is up to the teachers' discretion to incorporate the content (Mundy and Manion 2008). From teachers' perspectives this is problematic, since provincial curricula do not provide enough support or context for introducing GCE into the classroom (Mundy and Manion 2008; Schweisfurth 2006). However, some teachers have felt that the Ontario curriculum has provided ample opportunity to discuss global issues, and they had no problem finding space to incorporate these topics (Schweisfurth 2006). This experience implies that the incorporation of GCE in Canadian classrooms often requires motivation at the individual teacher level and without it, global issues may not be discussed.

Research shows a need for professional development for teachers in GCE. Although programs exist for teaching candidates to develop their understanding of global citizenship and how to interpret this in the classrooms, these programs are voluntary and thus, not all teacher candidates will access such experiences. In a study of 29 Grade six teachers, Leduc (2013) found that while teachers were discussing similar social justice concepts related to global citizenship, there was an identified need to improve the quality of GCE preparation for teachers. For example, McLean (2008) evaluated a program in Ontario consisting of events such as 
weekend retreats, conferences, and resource fairs, and found that the most likely candidates were women with previous education in peace and global education. Identified barriers to teaching GCE included minimal support from supervising teachers, lack of confidence in the material, and difficulty integrating GCE material into curriculum guidelines. Many non-mandated resources have been developed in Canada to aid educators teaching GCE such as the guide CIDA developed in 2007 titled the Global Classroom Initiative (Evans et al. 2009) and Educating for Global Citizenship in a Changing World: A Teacher's Resource Handbook (Evans et al. 2004). Resources such as these can help prepare teachers for conveying GCErelated topics not focused on in provincially mandated curriculum and act as needed supports that complement the training of teachers in service.

We acknowledge that GCE curricula sit within the context of globalization and are influenced in North America by the neo-liberal perspective focused on making people economic contributors, rather than global citizens, in both countries (Andreotti 2014; Hartung 2017). Although conceptualizations of Canada tend to characterize the country as not focused on being an economic powerhouse, educational reform in the 1990s mandated that curricula must address "perceived economic priorities" (Osborne 1992, p. 375). These policies have been revised, rewritten and now re-introduced, most recently in the province of Ontario. Within this political context, in addition to training a workforce, we note that Canada is a reference for promoting cultural tolerance within the nation, although not (yet) globally, and that this work is being implemented through different educational approaches related to GCE.

\section{Teaching Global Citizenship}

Moving past the rationales and history contextualizing GCE development in the U.S. and Canada, we turn to how educators are teaching global citizenship in schools. Broadly, global citizenship has been defined as "awareness, caring, and embracing cultural diversity, while promoting social justice and sustainability, coupled with responsibility to act" (Pierce et al. 2010, p. 167). Osborne (2000) suggests that citizenship education from a national perspective involves seven main elements: a sense of identity, awareness of and respect for the rights of others, the fulfillment of duties, critical acceptance of social values, political literacy, necessary academic skills, and personal reflection on these components. While there is a general agreement that educating youth is essential to citizenship, there are disagreements regarding how citizenship should be taught within the education system. For example, in Canada, some argue that the most impartial way to teach citizenship is to provide information on the debates surrounding Canada's national history, such as injustices faced by Indigenous Peoples, and Anglo- versus Franco-identities, while others have argued that instead, GCE should focus on character and service to ensure social stability (Osborne 2000). 
Teaching global citizenship has also been informed by traditional citizenship education, borrowing five main themes: a familiarity of related concepts; an identification with civic communities; an understanding of civil, political, socioeconomic, and cultural rights; personal reflexivity regarding citizen thinking; and an identification with values that lead to engagement in civic affairs (Evans et al. 2009). Furthermore, an analysis by Goren and Yemini (2017) suggests that between the two countries there are differences in how GCE is framed, as well as the dominant themes focused on by educators. For example, they highlight how Canadian GCE teaching strategies have focused on multiculturalism, immigration, and promoting tolerance, while U.S. approaches have focused on world political changes, understanding the global world, and maintaining the country's status of "world leader."

\section{Educational Pedagogies Related to GCE}

Beyond core curricula components and themes, GCE also merges with the educational pedagogies that influence school systems. Many GCE approaches advocate for world-mindedness, cross-cultural awareness, respect for the rights of others, and a social justice-oriented approach (Cook 2008; Eidoo et al. 2011; Evans et al. 2009; Osborne 2000). These values are especially relevant for the U.S. and Canada given the diversity of their populations, the complex intersections of race, ethnicity and culture, as well as the need to acknowledge and respond to legacies of colonization and systemic injustices. However, dominant, Eurocentric groups have long held the privilege of defining citizenship and structuring education systems to reflect their perspectives (Andreotti 2014; Young 1989). This context and history have resulted in the development of several educational approaches.

The importance of these pedagogies as they relate to GCE becomes apparent when you consider how GCE is currently taught in schools. Most GCE in public schools is woven into pre-existing subjects, such as social studies and civics, rather than existing as stand-alone course content (Orr and Ronayne 2009; Rapoport 2009). This lack of an explicit place in curriculum standards leaves educators with minimal institutional support for teaching GCE, many of whom may already be unfamiliar with the topic as it is, which consequently can lead to teachers postponing GCE education in favor of required content or presenting a superficial understanding of GCE packaged into more familiar concepts (Leduc 2013; Rapoport 2009 , 2010). For example, while the curriculum in Ontario, Canada provides many opportunities to discuss global citizenship, there is no emphasis on the topic when compared to other curricular demands. As such, only those who choose to prioritize GCE may seek out opportunities to integrate it into their classes (Schweisfurth 2006). Because contemporary GCE is mostly unstructured in the curricula, and it is subject to the knowledge and dedication of individual teachers, the pedagogies that inform educational systems can help support GCE and promote similar values. While present in both countries to differing degrees, the following pedagogical approaches are presented mainly within the Canadian context and include 
decolonizing pedagogies, a multiculturalism approach, as well as culturally responsive and anti-racist pedagogies.

\section{Decolonial Pedagogies}

Decolonizing pedagogies highlight the White, Eurocentric agenda of contemporary education systems, while also calling to attention their modes of colonization. As conceptualized by Orr and Ronayne (2009), where they refer to decolonial education as Indigeneity education, four elements are needed to promote Indigenous values within citizenship education. These include: Indigenous Traditionalism (the return to traditional Indigenous values); Harmony with Mother Earth (the defense of Indigenous land and focus on the significance of the environment); Indigenous selfdetermination (through decolonizing colonial mindsets, repositioning issues in ways that are relevant to Indigenous Peoples, and taking back control of decisions that have been made oppressive); and People to People and Nation to Nation (recognizing the importance of peace between Peoples and nations). Orr and Ronayne argue that many GCE initiatives still uphold the colonial harm of dominant cultures and as such, may not always be a suitable approach in education. Focusing on Canada, their research concludes that while Band-operated schools (i.e., schools that are under the political jurisdiction of First Nations governments) tend to be supported by policies that facilitate the inclusion of Indigenous knowledge, provincial education policies are currently structured such that teaching these four pillars of Indigeneity is left to the discretion of teachers. This absence of a system makes it difficult for all Canadian students to be exposed to Indigenous issues in school, resulting in recommendations for more support from school boards and teacher education institutions so that schools can collaborate with Indigenous organizations to promote a decolonial framework.

\section{Multiculturalism}

In Canada, provincial curricula have been endorsing a multiculturalism approach since the 1970s, with a focus on embracing cultural diversity (Raby 2004). Multiculturalism seeks to highlight differences among groups in positive ways but often takes an apolitical, ahistorical stance, opting instead for a focus on celebration and an assumption of an egalitarian society where all groups are treated equally (Kishimoto 2018). While this approach may have been developed to promote empathy and acceptance, it has suffered from many shortcomings. Educational strategies that exclusively focus on celebrating culture run the risk of de-politicizing racism discourse, homogenizing cultures to create "us" versus "them" binaries, as well as reinforcing harmful power structures and the continual centering of White experience (Bedard 2000; Eidoo et al. 2011; Kishimoto 2018; Raby 2004). Eidoo et al. 
(2011) argue that GCE is already strongly linked to a multiculturalism approach because global education is seen to be inherent in cultural education. This link means that GCE can be susceptible to the same critiques leveled against multiculturalism, whereby a superficial focus on the similarities of individuals can ignore realities of power dynamics and oppression as well as support an underlying neoliberal, Eurocentric bias (Andreotti 2014; Eidoo et al. 2011; Hartung 2017). However, a GCE framework done critically can contribute to a stronger version of the multicultural approach by providing a nuanced understanding of settlement, immigration and pluralistic identities by acknowledging and addressing the dynamics between marginalized and dominant cultures (Eidoo et al. 2011).

\section{Culturally Responsive Pedagogy}

An alternative educational approach that is finding traction is Culturally Responsive Pedagogy, which focuses on respecting and understanding the complexities of student difference as well as integrating a student's prior knowledge and experience into the classroom (Gay 2000; Ladson-billings 1995; Ontario Ministry of Education 2013). Culturally responsive teaching is closely tied to youth engagement through its commitment to having students view themselves as valuable contributors to their communities, as well as its promotion of student empowerment by having youth use their experiences and culture to foster positive environments (Grant and Asimeng-boahene 2006; Ladson-billings 1995). Connecting culturally responsive pedagogy back to GCE, this approach has been directly linked to GCE by researchers in the U.S. as they explored the incorporation of African proverbs into citizenship education curriculum for urban schools, as a way of encouraging educators to implement teaching strategies that reflect the cultural traditions of their students (Grant and Asimeng-boahene 2006). Furthermore, culturally responsive pedagogy has a social justice-oriented standpoint that emphasizes the use of teaching to promote student equity, which is similar to anti-racist educational approaches.

\section{Anti-racist Pedagogy}

Given the limitations of the multiculturalism approach, some scholars have argued for the incorporation of anti-racist pedagogy into educational systems. Informed by Critical Race Theory, an anti-racist approach requires a political stance, aligning itself with social justice by critically reflecting on the power dynamics and institutional contributions that sustain racism (Kishimoto 2018; Raby 2004). The integration of an anti-racist approach provides the opportunity for a deeper engagement with concepts such as racism and seeks to diversify our understandings of race, nationhood and what it means to be a national citizen, using history and critical 
analysis to illustrate how these concepts have been shaped to benefit dominant groups (Bryan 2012; Dei 2000; Kishimoto 2018; Raby 2004; Skerrett 2011). Research has shown that there is support among teachers for a stronger focus on anti-racism approaches, but there is currently a lack of structural support from schools for promoting anti-racist education (Skerrett 2011).

The aforementioned educational strategies all seek to center diversity in one way or another with culturally responsive pedagogy and anti-racism taking explicitly political stances towards a social justice orientation, thus connecting to fundamental core values of GCE (illustrated next).

\section{Case Example: Racialized Students' Relationship to Canadian Curricula}

When implementing GCE into public schools, educators need to be attuned to the diversity of their students and actively seek to understand and ameliorate the power dynamics and oppression marginalized students face in mainstream education. Not doing so means that you run the risk of not just reducing the efficacy of your teachings but, more importantly, contributing to the systemic-based harm students experience in school. A one-size-fits-all approach to GCE only serves to gloss over these issues, reduces students' critical engagement in their learning, and does a disservice to the core values GCE claims to uphold. As an example of the problems with not addressing core biases and generalizations, we turn to the Canadian school system and its contributions to perpetuating racism towards racialized students.

The Canadian public education system continues to be limited by its inability to work for all students, mainly being influenced by a White, Eurocentric curriculum at the cost of marginalized students (Dei et al. 2000; Kishimoto 2018; Parhar and Sensoy 2011; Zinga and Gordon 2016). Education has a direct impact on the lives of many people, and it continues to be a factor helping to produce and maintain racism in society (Bryan 2012). For instance, being in a school space can expose racialized students to acts of racism or negative stereotyping by peers or staff, where experiences of discrimination are linked to adverse academic and psychosocial outcomes for youth (Codjoe 2001; Deutsch and Jones 2008; Livingstone and Weinfeld 2017). Additionally, the existence of institutional racism in Canadian schools has been well-documented, where racialized youth are often subjected to exclusionary educational practices, misrepresentation, and having their experiences challenged while those from dominant groups are recognized (Codjoe 2001; Parhar and Sensoy 2011; Zinga and Gordon 2016).

These issues can be compounded by narrow, individualized understandings of racism, which allow for systemic or subtle racism to be downplayed or denied (Bryan 2012; Raby 2004; Zinga and Gordon 2016). The negative effects of this conceptualization become apparent when youth engage in discussions about racism. In two separate studies documenting Ontario secondary students' perceptions of 
racism in their schools, Zinga and Gordon (2016) and Raby (2004) found that students denied or downplayed racist incidents in their school environment, even while providing examples of racism. This tendency was the case for the majority of all the students, although racialized students were overall more aware and open to discussing racism than their peers. Furthermore, students in both studies often attributed racist events to individual factors without acknowledging or perceiving connections to systemic racism. It is because of this pervasiveness of racism, and its negative effects on students, that the education system needs to adopt educational frameworks that openly acknowledge these concerns and seek to rectify the situation with more responsible and intentional pedagogical approaches.

One way to implement anti-racist education into schools, as well as promote youth engagement, is through youth-adult partnerships that focus on social justice and power. Previous research has acknowledged that youth care about their school environment because many of them spend a large part of their lives in educational settings and they seek to be included in decision-making processes related to equity (Checkoway 2011). Some partnerships between youth and adults have helped spur on GCE-related dialogues in educational settings by developing community events and awareness campaigns that center on racism and human rights (Cooper et al. 2013). School-based partnerships is a research area in its infancy, with studies still trying to identify core elements for successfully implementing and sustaining these groups in authority-driven school settings (Cooper et al. 2013; Deutsch and Jones 2008; Linds et al. 2013). The above illustration leads us to broaden the conceptualization of GCE to engaging youth as a means for realizing global peace, human rights and equity.

\section{Youth Engagement}

We reason that in the U.S. and Canada the most effective approach to GCE is through youth engagement, which can be broadly conceptualized as involving young people in their institutions, communities and decisions (Checkoway and Gutiérrez 2006). Western discourses on GCE are already closely linked to the concept of youth engagement (Hartung 2017), and act as a way of combatting common public perceptions of youth as unmotivated in civic engagement or failing to contribute to political activities (Ballard et al. 2016; Youniss et al. 2002). Barring youth from contributing to major decisions that affect their lives has often been justified by characterizing them as lacking expertise or an understanding of the negative impacts of ill-informed decisions (Blanchet-Cohen et al. 2013; Bulling et al. 2013). When negative messages are disseminated from authority-level adults, these beliefs can become internalized by young people, reducing their capacity to see themselves as agents of change in their own lives and contributing to their disengagement (Checkoway 2011; Checkoway and Gutiérrez 2006; Finn 2001). Citing a lack of competency and initiative to justify excluding youth only further contributes to their isolation, preventing opportunities to develop competencies and discouraging young 
people from seeking out involvement (Bulling et al. 2013). GCE's focus on youth engagement contrasts this perception by representing youth as responsible, democratic members of the world who can meaningfully contribute to the social and political arenas in which they have been typically excluded (Hartung 2017).

The outcomes of youth engagement can be seen at the local level in organizations and communities that provide opportunities for meaningful youth involvement. Young people are in the best position to understand their rapidly evolving world, including how it intersects with advancements in technology and social media. As such, their involvement in political and social spheres can provide valuable insights, increase youths' sense of community and allow young people to act as agents of change, positively impacting both themselves and community development (Checkoway and Gutiérrez 2006; Perkins et al. 2001; Wong et al. 2010; Zeldin et al. 2005; Zimmerman et al. 2011). In school settings, involving youth in decisionmaking processes have contributed to the sustainability and long-term impacts of school-based programming (Menesini et al. 2012; Paluck et al. 2016), as well as fostered students' relationships with influential adults (Mitra 2004; Wong et al. 2010). Transformative youth-adult relationships, such as those developed out of these opportunities for youth engagement, can also be a resource for well-being acting as a protective factor against psychological and social problems, especially among marginalized youth (Sterrett et al. 2011; Ungar 2013). At a broader level, youth participation has been shown to increase public knowledge and encourage future democratic action (Zeldin et al. 2013). Researchers have proposed that how older generations conceptualize political engagement may no longer be relevant, with a growing interest by youth in unconventional forms of civic participation and a willingness to mobilize for issues directly related to their generation, such as environmental justice, educational reform, and internet laws (Ballard et al. 2016; Checkoway et al. 2005; Shaw-Raudoy and Mcgregor 2013; Youniss et al. 2002). The widescale impacts of these types of issues link youth engagement in these areas to the tenants of GCE discussed previously in this chapter.

As an example of the effects of youth engagement at the global level we turn to immigrant-led youth movements in the U.S. that engage in border activism. Primarily organized by Latino youth, young people have been advocating for the rights of undocumented immigrants and protesting the militarization of the U.S.Mexico border through large-scale protests, developing national activist networks, sit-ins along the border and at immigration offices, as well as public demonstrations of undocumented youth crossing the border back into the U.S. (Burridge 2010; Ribero 2018; Solis 2018; Zimmerman 2011). Furthermore, these movements are situated within an era flooded with technology, where social media can play a significant role in broadening the impacts of social movements by facilitating the creation of support networks as well as the dissemination of non-dominant discourses (Mundt et al. 2018). In our current example, youth have been utilizing technology in novel ways to encourage the public to reconceptualize citizenship. Young people are using social media platforms to get their voices into the discussion, while the internet provides opportunities for organizing by building up advocacy networks nationally and across the globe (Zimmerman 2011). By focusing on international 
human rights, nation-imposed borders, and immigration justice, youth-led border activism acts as an exemplar for how youth engagement can be scaled up to influence conceptualizations of citizenship as well as address multinational issues.

A crucial component for meaningful youth participation is having supportive adults acting as resources and allies, thus making youth-adult partnerships a vehicle for youth engagement (Shaw-Raudoy and Mcgregor 2013; Zeldin et al. 2013). Youth-adult partnerships involve multiple youth and adults collectively working together over time to promote social justice (Zeldin et al. 2013), which connects with the core tenants of GCE. While many partnership best practices can be found in the literature, we want to highlight the need for additional considerations when working with marginalized youth, where social and political contexts may make collaborative environments unsafe. For example, while racialized youth want to be involved in participatory projects, adults need to be critically aware of power dynamics and willing to invest more effort to gain trust, build relationships and secure buy-in (Fine et al. 2003; Ginsburg et al. 2002; Wong et al. 2010). Furthermore, while youth engagement in GCE may have the potential to foster innovation and empowerment, it comes with several unique challenges. One barrier, found in partnerships, involves a misguided understanding of power-sharing dynamics.

Given that adults often come in with a disproportionate amount of power, members may fall into the trap of believing that to be equitable with power-sharing youth must do everything of importance. This misperception limits adults' ability to collaborate effectively and places the burden of responsibility on youth (Camino 2005; Evans and Lund 2013; Shaw-Raudoy and Mcgregor 2013). Another barrier is that the youth engagement field is new and lacks long-established research and practice base. As such, many institutions, such as education systems, view youth engagement, and their ensuring partnerships, as modern concepts and are reluctant to invest resources into them (Zeldin et al. 2005). Finally, properly doing youth engagement requires adequate time and flexibility (Shaw-Raudoy and Mcgregor 2013), which can conflict with the rigid structures and time limitations of a school environment. While difficult, addressing these challenges may help avoid common pitfalls or mitigate some of their harmful effects.

\section{Conclusion}

We began with an overview of the political, social, and historical contexts that have shaped how GCE is conceptualized and taught in Canada and the U.S. Given the lack of well-defined, supported curricula for global citizenship, an overview is instead provided of educational pedagogies that incorporate core GCE tenants. Components of GCE can be found in decolonial pedagogies, multiculturalism approaches, as well as anti-racist and culturally responsive pedagogies. From there, we recommend that GCE in Canada and the U.S. shift towards a youth engagement approach in the form of youth-adult partnerships. While challenges exist for promoting meaningful youth engagement, incorporating youth voice into the 
implementation of GCE holds the potential to increase the impact, relevance and sustainability of global citizenship curricula. If Canada and the U.S. were to move forward with incorporating youth engagement into GCE, it would need to be an intentional effort demonstrated by institutional support through the provision of clear guidelines, comprehensive resources, and adequate training for educators.

We agree with Akkari \& Maleq (Chap. 1, this volume) that GCE can only be realized by applying, in ways adapted to local contexts, the three distinctive frameworks of education: sustainable development, citizenship education, and intercultural education. We also observe that these frameworks can contribute to realizing many of the SDGs. We argue for GCE curricula to focus on addressing gender equality (SDG 5), reduced inequalities (SDG 10), and partnerships (SDG 17) across countries, within countries and across the generations, particularly with youth. We propose that youth engagement is a critical factor in rendering GCE relevant to local contexts as well as to the international sustainable development agenda.

When developing a GCE curriculum for Canada or the U.S., we suggest considering the following questions. How will the learning objectives influence more broadly the next generation of voters, policymakers, politicians, and world leaders on issues such as gender equality, poverty, and social justice? Will GCE build borders around nationality and citizenship or will it build bridges across countries that support the mobility inherent to global trade? From a global worldview, what is the relation between mobility, immigration, migration, peace and security? A highquality GCE will address these questions, and many others, including the role that citizenship plays in governing nations (for more information see Globalizing Citizenship by Kim Rygiel 2010). While we suggest the pathway of youth engagement for Canada and the U.S., it is critical that any future GCE conceptualizations move from a traditional nation-centric stance to one that fully embraces and supports the "global" in global citizenship.

\section{References}

Akkari, A., \& Loomis, C. (1998). Toward a new understanding of language minority students' experiences of bilingual education in the United States. Bulletin Suisse de Linguistique Appliquée, 67, 31-59.

Andreotti, V. (2014). Postcolonial perspectives on global citizenship education. New York: Routledge.

Ballard, P. J., Cohen, A. K., \& Littenberg-Tobias, J. (2016). Action civics for promoting civic development: Main effects of program participation and differences by project characteristics. American Journal of Community Psychology, 58(3-4), 377-390.

Banks, J. A. (2008). Diversity, group identity, and citizenship education in a global age. Educational Researcher, 37(3), 129-139.

Banks, J. A. (2009). Human rights, diversity, and citizenship education. The Educational Forum, $73,100-110$. 
Bedard, G. (2000). Deconstructing whiteness: Pedagogical implications for anti-racism education. In G. J. S. Dei \& A. Calliste (Eds.), Power, knowledge and anti-racism education: A critical reader (pp. 41-56). Halifax: Fernwood Publishing.

Blanchet-Cohen, N., Linds, W., Mann-Feder, V., \& Yuen, F. (2013). Introduction to the special issue on transforming practices: Emancipatory approaches to youth engagement. International Journal of Child, Youth and Family Studies, 3, 320-327.

Bryan, A. (2012). 'You've got to teach people that racism is wrong and then they won't be racist': Curricular representations and young people's understandings of 'race' and racism. Journal of Curriculum Studies, 44(5), 599-629.

Bulling, D., Carson, L., DeKraai, M., Garcia, A., \& Raisio, H. (2013). Deliberation models featuring youth participation. International Journal of Child, Youth and Family Studies, 3, 409-432.

Burridge, A. (2010). Youth on the line and the No Borders movement. Children's Geographies, $8(4), 401-411$.

Camino, L. (2005). Pitfalls and promising practices of youth-adult partnerships: An evaluator's reflections. Journal of Community Psychology, 33(1), 75-85.

Checkoway, B. (2011). What is youth participation? Children and Youth Services Review, 33 (2), 340-345

Checkoway, B., \& Gutiérrez, L. (2006). Youth participation and community change: An introduction. Journal of Community Practice, 14(1-2), 1-9.

Checkoway, B., Allison, T., \& Montoya, C. (2005). Youth participation in public policy at the municipal level. Children and Youth Services Review, 27(10), 1149-1162.

Codjoe, H. M. (2001). Fighting a "public enemy" of Black academic achievement: The persistence of racism and the schooling experiences of Black students in Canada. Race Ethnicity and Education, 4(4), 343-375.

Cook, S. A. (2008). Give peace a chance: The diminution of peace in global education in the United States, United Kingdom, and Canada. Canadian Journal of Education, 31(4), 889-913.

Cooper, A., Nazzari, V., King, J. K. K., \& Pettigrew, A. (2013). Speaking rights: Youth empowerment through a participatory approach. International Journal of Child, Youth and Family Studies, 3, 489-501.

Cummins, J. (1992). Heritage language teaching in Canadian schools. Journal of Curriculum Studies, 24(3), 281-286.

Dei, G. J. S. (2000). Towards an anti-racism discursive framework. In G. J. S. Dei \& A. Calliste (Eds.), Power, knowledge and anti-racism education: A critical reader (pp. 23-40). Halifax: Fernwood Publishing.

Dei, G. J. S., James, I. M., Karumanchery, L. L., James-Wilson, S., \& Zine, J. (2000). Removing the margins: The challenges and possibilities of inclusive schooling. Toronto: Canadian Scholars Press Publishing.

Deutsch, N. L., \& Jones, J. N. (2008). "Show me an ounce of respect": Respect and authority in adult-youth relationships in after-school programs. Journal of Adolescent Research, 23(6), $667-688$.

Eidoo, S., Ingram, L. A., Macdonald, A., Nabavi, M., Pashby, K., \& Stille, S. (2011). Through the kaleidoscope: Intersections between theoretical perspectives and classroom implications in critical global citizenship education. Canadian Journal of Education, 34(4), 59-85.

Evans, R. E., \& Lund, D. E. (2013). Forging ethical adult-youth relationships within emancipatory activism. International Journal of Child, Youth and Family Studies, 3, 433-443.

Evans, M., Reynolds, C., \& Ast, D. (Eds.). (2004). Educating for global citizenship in a changing world: A teacher's resource handbook. Toronto: OISE/UT. http://cide.oise.utoronto.ca/globalcitizenship.php

Evans, M., Ingram, L. A., Macdonald, A., \& Weber, N. (2009). Mapping the "global dimension" of citizenship education in Canada: The complex interplay of theory, practice and context. Citizenship Teaching and Learning, 5(2), 17-34. 
Fine, M., Freudenberg, N., Payne, Y., Perkins, T., Smith, K., \& Wanzer, K. (2003). "Anything can happen with police around": Urban youth evaluate strategies of surveillance in public places. Journal of Social Issues, 59(1), 141-158.

Finn, J. (2001). Text and turbulence: Representing adolescence as pathology in the human services. Childhood, 8, 167-191.

Gay, G. (2000). Culturally responsive teaching: Theory, practice \& research. New York: Teachers College Press.

Ginsburg, K. R., Alexander, P. M., Hunt, J., Sullivan, M., \& Cnaan, A. (2002). Enhancing their likelihood for a positive future: Focus groups reveal the voice of inner-city youth. Pediatrics, 109(6), 95.

Goren, H., \& Yemini, M. (2017). Citizenship education redefined: A systematic review of empirical studies on global citizenship education. International Journal of Educational Research, 82, $170-183$.

Grant, R. A., \& Asimeng-boahene, L. (2006). Culturally responsive pedagogy in citizenship education: Using African proverbs as tools for teaching in urban schools. Multicultural Perspectives, $8(4), 17-24$.

Hartung, C. (2017). Global citizenship incorporated: Competing responsibilities in the education of global citizens. Discourse: Studies in the Cultural Politics of Education, 38(1), 16-29.

Kishimoto, K. (2018). Anti-racist pedagogy: From faculty's self-reflection to organizing within and beyond the classroom. Race Ethnicity and Education, 21(4), 540-554.

Kniep, W. M. (1986). Defining a global education by its content. Social Education, 50(6), 437-446.

Ladson-billings, G. (1995). Toward a theory of culturally relevant pedagogy. American Educational Research Journal, 32(3), 465-491.

Leduc, R. (2013). Global citizenship instruction through active participation: What is being learned about global citizenship? The Educational Forum, 77, 394-406.

Linds, W., Sammel, A., \& Goulet, L. (2013). Dancing together: A conversation about youth and adult relational authority in the context of education. International Journal of Child, Youth and Family Studies, 3, 337-356.

Livingstone, A., \& Weinfeld, M. (2017). Black students and high school completion in Quebec and Ontario: A multivariate analysis. Canadian Sociological Association, 54(2), 174-197.

McLean, L. R. (2008). Imagining global citizens: Teaching peace and global education in a teacher-education programme. Citizenship Teaching and Learning, 4(1), 50-64.

Menesini, E., Nocentini, A., \& Palladino, B. E. (2012). Empowering students against bullying and cyberbullying: Evaluation of an Italian peer-led model. International Journal of Conflict and Violence, 6(2), 314-321.

Mitra, D. L. (2004). The significance of students: Can increasing "student voice" in schools lead to gains in youth development? Teachers College Record, 106(4), 651-688.

Mundt, M., Ross, K., \& Burnett, C. M. (2018). Scaling social movements through social media: The case of Black Lives Matter. Social Media and Society, 1-14.

Mundy, K., \& Manion, C. (2008). Global education in Canadian elementary schools: An exploratory study. Canadian Journal of Education, 31(4), 941-974.

Myers, J. P. (2010). 'To benefit the world by whatever means possible': Adolescents' constructed meanings for global citizenship. British Educational Research Journal, 36(3), 483-502.

Nussbaum, M. C. (2010). Kant and cosmopolitanism. In G. W. Brown \& D. Held (Eds.), The cosmopolitanism reader (pp. 27-44). Cambridge: Polity Press.

Ontario Ministry of Education. (2013). Culturally responsive pedagogy. Retrieved from http:// www.edu.gov.on.ca/eng/literacynumeracy/inspire/research/CBS_ResponsivePedagogy.pdf

Orr, J., \& Ronayne, B. (2009). Indigeneity education as Canadian First Nations citizenship education. Citizenship Teaching and Learning, 5(2), 35-49.

Osborne, K. (1992). The emerging agenda for Canadian high schools. Journal of Curriculum Studies, 24, 371-379.

Osborne, K. (2000). Public school and citizenship education in Canada. Canadian Ethnic Studies, $32(1), 8-37$. 
Paluck, E. L., Shepherd, H., \& Aronow, P. M. (2016). Changing climates of conflict: A social network experiment in 56 schools. Proceedings of the National Academy of Sciences of the United States of America, 113(3), 566-571.

Parhar, N., \& Sensoy, O. (2011). Culturally relevant pedagogy redux: Canadian teachers' conceptions of their work and its challenges. Canadian Journal of Education, 34(2), 189-218.

Perkins, D. F., Borden, L. M., \& Villarruel, F. A. (2001). Community youth development: A partnership for action. School Community Journal, 11, 39-56.

Pierce, L., Reysen, S., \& Katzarska-Miller, I. (2010). The search for a definition of global citizenship. In S. Reysen (Chair) (Ed.), Global citizenship: Americans within the world. Symposium conducted at the 54th annual meeting of the American Studies Association of Texas, Commerce, TX.

Raby, R. (2004). “There's no racism at my school, it's just joking around": Ramifications for antiracist education. Race Ethnicity and Education, 7(4), 367-383.

Rapoport, A. (2009). A forgotten concept: Global citizenship education and state social studies standards. The Journal of Social Studies Research, 33(1), 91-113.

Rapoport, A. (2010). We cannot teach what we don't know: Indiana teachers talk about global citizenship education. Education, Citizenship and Social Justice, 5(3), 179-190.

Ribero, A. M. (2018). Drifting across the border: On the radical potential of undocumented im/ migrant activism in the US. Performance Research, 23(7), 95-102.

Rygiel, K. (2010). Globalizing citizenship. Vancouver: UBC Press.

Schweisfurth, M. (2006). Education for global citizenship: Teacher agency and curricular structure in Ontario schools. Educational Review, 58(1), 41-50. https://doi. org/10.1080/00131910500352648.

Shaw-Raudoy, K., \& Mcgregor, C. (2013). Co-learning in youth-adult emancipatory partnerships: The way forward? International Journal of Child, Youth and Family Studies, 3, 391-408.

Skerrett, A. (2011). English teachers' racial literacy knowledge and practice. Race Ethnicity and Education, 14(3), 313-330.

Solis, G. (2018, March 12). In El Paso, immigrant youth are changing the face of border activism. Retrieved from https://www.vice.com/en_ca/article/8xdjap/ dreamers-immigrant-youth-are-changing-border-activism

Sterrett, E. M., Jones, D. J., Mckee, L. G., \& Kincaid, C. (2011). Supportive non-parental adults and adolescent psychosocial functioning: Using social support as a theoretical framework. American Journal of Community Psychology, 48, 284-295.

Ungar, M. (2013). The impact of youth-adult relationships on resilience. International Journal of Child, Youth and Family Studies, 3, 328-336.

United Nations. (2015). Transforming our World: The 2030 Agenda for Sustainable Development, General Assembly Resolution A/Res/70/1, Sustainable Development Knowledge Platform. Available at: https://sustainabledevelopment.un.org/post2015/transformingourworld. Site accessed 10 Nov 2018.

Vladimirova, K., \& Le Blanc, D. (2016). Exploring links between education and sustainable development goals through the lens of UN flagship reports. Sustainable Development, 24, 254-271. Available from: https://doi.org/10.1002/sd.1626. Retrieved May 4, 2018.

Wong, N. T., Zimmerman, M. A., \& Parker, E. A. (2010). A typology of youth participation and empowerment for child and adolescent health promotion. American Journal of Community Psychology, 46, 100-114.

Young, I. M. (1989). Polity and group difference: A critique of the ideal of universal citizenship. Ethics, 99, 250-274.

Youniss, J., Bales, S., Diversi, M., \& Silbereisen, R. (2002). Youth civic engagement in the twentyfirst century. Journal of Research on Adolescence, 12(1), 121-148.

Zeldin, S., Camino, L., \& Mook, C. (2005). The adoption of innovation in youth organizations: Creating the conditions for youth-adult partnerships. Journal of Community Psychology, 33(1), 121-135. 
Zeldin, S., Christens, B. D., \& Powers, J. L. (2013). The psychology and practice of youth-adult partnership: Bridging generations for youth development and community change. American Journal of Community Psychology, 51, 385-397.

Zimmerman, M. A. (2011). A dream detained: Undocumented Latino youth and the DREAM movement. NACLA Report on the Americas, 44, 14-17.

Zimmerman, M. A., Stewart, S. E., Morrel-Samuels, S., Franzen, S., \& Reischl, T. M. (2011). Youth empowerment solutions for peaceful communities: Combining theory and practice in a community-level violence prevention curriculum. Health Promotion Practice, 12(3), 425-439.

Zinga, D. M., \& Gordon, M. K. (2016). 'Racism under the radar': Student perceptions of school experiences in a multicultural context. Race Ethnicity and Education, 19(5), 1088-1116.

Open Access This chapter is distributed under the terms of the Creative Commons Attribution 4.0 International License (http://creativecommons.org/licenses/by/4.0/), which permits use, duplication, adaptation, distribution and reproduction in any medium or format, as long as you give appropriate credit to the original author(s) and the source, a link is provided to the Creative Commons licence and any changes made are indicated.

The images or other third party material in this chapter are included in the work's Creative Commons licence, unless otherwise indicated in the credit line; If such material is not included in the work's Creative Commons licence and the respective action is not permitted by, users will need to obtain permission from the license holder to duplicate, adapt or reproduce the material.

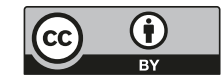

